\title{
UMA ANÁLISE CRÍTICO-REFLEXIVA DA COMPREENSÃO DA ADOÇÃO DOS ARTEFATOS DE CONTABILIDADE GERENCIAL SOB UMA LENTE ALTERNATIVA - A CONTRIBUIÇÃO DE ABORDAGENS ORGANIZACIONAIS
}

\section{A CRITIC-REFLEXIVE ANALYSIS OF THE COMPREHENSION OF THE ADOPTION OF ACCOUNTING ARTIFACTS UNDER AN ALTERNATIVE VIEW - THE CONTRIBUTION OF ORGANIZATIONAL APPROACHES}

\author{
MARCIA MARIA DOS SANTOS BORTOLOCCI ESPEJO \\ Doutora em Controladoria e Contabilidade pela \\ Universidade de São Paulo \\ Professora Adjunta do Setor de Ciências Sociais Aplicadas da \\ Universidade Federal do Paraná \\ Curitiba/PR, Brasil \\ E-mail: marciabortolocci@ufpr.br
}

ANA PAULA CAPUANO DA CRUZ

Mestranda em Contabilidade na

Universidade Federal do Paraná

Curitiba/PR, Brasil

E-mail: anapaulacapuanodacruz@hotmail.com
FLAVIANO COSTA

Mestrando em Contabilidade na

Universidade Federal do Paraná

Curitiba/PR, Brasil

E-mail: flaviano_costa@hotmail.com

LAURO BRITO DE ALMEIDA

Doutor em Contabilidade pela Universidade de São Paulo Professor Adjunto do Setor de Ciências Sociais Aplicadas da Universidade Federal do Paraná Curitiba/PR, Brasil

E-mail: brito@ufpr.br

\section{Resumo}

Por meio de um ensaio teórico, procurou-se identificar se as abordagens organizacionais psicológica, contingencial e institucional contribuem para a compreensão da utilização dos artefatos de contabilidade gerencial. Com a finalidade de compartilhar lentes alternativas para justapor visões e propiciar o estudo de interacões e relacõos de interdependência organizacionais, a análise crítico-reflexiva realizada denota o potencial contributivo de tais teorias organizacionais na promoção de uma melhor compreensão no processo de utilização dos artefatos contábeis gerenciais. No tocante à abordagem psicológica, especialmente no que tange à psicologia analítica, destaca-se que a importância do uso do ferramental representado pela contabilidade no processo de maximização do valor das empresas deve ser transferida para o nível da consciência. Quanto à abordagem contingencial, a reflexão remete à necessidade de identificação de uma combinação entre fatores contingenciais e os artefatos contábeis gerenciais que representem o melhor encaixe e consequentemente contribuam a um desempenho superior. Com relação à contribuição da abordagem institucional, visualiza-se o auxílio no processo de construção de conhecimento sobre a prática contábil e não para a prática da contabilidade. Salienta-se que a presente discussão possui implicações de naturezas acadêmicas e profissionais, estimulando conexões multidisciplinares com outras ciências no que tange às pesquisas da área. Adicionalmente, sugere-se uma aproximação da profissão contábil da gestão, inclusive em sua formação, incrementando sua capacidade analítica. À luz dessas considerações, evidencia-se uma proposta de quebra de paradigma, orientada para uma visão mais ampla da pesquisa contábil que venha a contribuir sobremaneira à inserção da pesquisa brasileira no cenário internacional e a um profícuo alinhamento entre as necessidades empresarias e os objetivos da contabilidade gerencial.

Palavras-chave: psicologia analítica; Teoria da Contingência; Teoria Institucional.

\section{Abstract}

By means of a theoretical rehearsal it was tried identify if the organizational approaches psychological, contingential and institutional contribute for the comprehension of the utilization of the artefacts of managerial accounting. With the purpose of share alternative lenses to juxtapose visions and to propitiate the organizational interdependence and relations interactions study, the accomplished critic-reflexive analysis denotes the contributive potential of such organizational theories in the promotion of a better comprehension in the utilization process of the managerial accounting artefacts. Concerning the psychological approach, especially in that tolls to the analytic psychology, highlights that the importance of the use of ferramental represented by accounting in success process of the value of the companies should be transferred to the level of the conscience. Regarding the contingential approach, the reflection remits to the need to identification of a combination between contingential factors and the managerial accounting artefacts that represent the best conexion and consequently contribute to a superior performance. With regard to the contribution of the institutional approach, it visualizes the help in the knowledge construction process on the accounting practice and not for the practice of the accounting. It points out that for discussion present owns implications of academic and professional natures, stimulating multidiscipline connections with other sciences in that tolls to the researches of the area. Additionally, it suggests an approach of the accounting career of the administration, inclusive in your formation, increasing your analytic capacity. To the light of these considerations, it evidences a paradigm breakage proposal, guided for a wider vision of the accounting research that comes to contribute excessively to the insert of the Brazilian research in the international scenery and to an useful alignment among entrepreneurial needs and the goals of the managerial accounting.

Key words: analytical psychology, Contingency Theory, Institutional Theory. 


\section{INTRODUÇÃO}

O cenário ambiental contemporâneo tem demandado flexibilidade e capacidade de adaptação às mudanças por parte das organizações. Nesse sentido, a competitividade tem compelido as empresas a repensarem suas práticas gerenciais e estratégias para ampliar a exploração de oportunidades de negócios. Assim, a opção por uma determinada estratégia, em geral, requer a adoção de um artefato contábil gerencial para atender às demandas de informações específicas. Considerando o entendimento de Guerreiro, Frezatti e Casado (2006, p. 10), de que a missão da contabilidade gerencial é justamente “[...] prover informações adequadas para que os tomadores de decisões maximizem o resultado econômico de suas decisões", percebe-se que o sucesso organizacional pode estar condicionado pelo conteúdo informacional orientativo dos processos de gestão e, consequentemente, pelas informações que os artefatos de contabilidade gerencial podem fornecer.

No Brasil, o crescente interesse pelo desenvolvimento de pesquisas em contabilidade gerencial respaldadas por abordagens organizacionais alternativas à racionalidade econômica (SOUTES \& DE ZEN, 2005; GUERREIRO, FREZATTI \& CASADO, 2006; REIS \& PEREIRA, 2007; SANTOS, ALMEIDA E CROZATTI, 2007; ESPEJO, 2008), sugere a importância de identificar e compreender os fatores que influenciam a adoção dos artefatos contábeis gerenciais, visto que um ambiente em constante processo de transformação, além de se mostrar desafiador para muitas empresas, instiga questionamentos acerca do melhor curso de ação às atividades organizacionais.

Em adição, ressalta-se que a exploração do potencial contributivo das teorias organizacionais, considerando as ciências da sociologia e psicologia, associadamente à contabilidade gerencial, representa uma oportunidade de pesquisa. Alinhadamente a essa proposição argumentativa, Ittner e Larcker (2002) expõem que o respaldo à tomada de decisão não é privilégio da racionalidade econômica, sugerindo que o desenvolvimento de estudos interdisciplinares relativos à contabilidade gerencial merece maior aprofundamento.

A proposição de que a sobrevivência de um sistema é vinculada à integração entre os seus componentes estruturais, tendo em vista que tais componentes são partes interrelacionadas do todo (TOLBERT \& ZUCKER, 1999) conduz à visualização de que o estudo de artefatos de contabilidade gerencial sob lentes pouco discutidas proporciona melhores esclarecimentos acerca das empresas como um todo. Reis e Pereira (2007) acrescentam que estudos relativos a associações entre a contabilidade gerencial e as teorias organizacionais auxiliam na compreensão de fenômenos intra-organizacionais.

Assim, com base nos argumentos supracitados, a questão orientadora do presente estudo é: as abordagens organizacionais psicológica, contingencial e institucional contribuem para a compreensão da adoção dos artefatos de contabilidade gerencial? 0 objetivo subjacente nesse enunciado é verificar se as abordagens organizacionais citadas $a$ anteriori contribuem para a compreensão da utilização dos artefatos de contabilidade gerencial.

Nesse sentido, a proposta é desenvolver uma análise crítica contraponto os principais estudos que respaldam a discussão proposta, estimulando um processo reflexivo acerca de elementos relacionados à adoção dos artefatos contábeis gerenciais. O foco é trabalhar a visão de "compartilhar lentes alternativas", justapondo abordagens para estudar as interações e as relações de interdependência organizacionais. Desse modo, a presente investigação configura-se, metodologicamente, como um ensaio teórico. Assim, acredita-se estar contribuindo para o entendimento das práticas de contabilidade gerencial nas organizações, bem como para uma melhor exploração de seus benefícios. 
0 presente ensaio está estruturado em mais quatro seções. Na segunda seção temse um panorama da contabilidade gerencial e de seus artefatos. A seguir, a seção 3 explora abordagens organizacionais alternativas selecionadas à condução da presente discussão. $\mathrm{Na}$ quarta seção, tem-se uma exposição do diálogo da contabilidade gerencial com tais abordagens. Por fim, a quinta seção reúne um fechamento do questionamento posto à reflexão, atentando à importância da conversação entre a escolha de artefatos contábeis gerenciais e as contribuições das abordagens psicológica, contingencial e institucional.

\section{ARTEFATOS DE CONTABILIDADE GERENCIAL}

A contabilidade gerencial configura-se como um processo que identifica, mensura, acumula, analisa, prepara, interpreta e comunica informações aos gestores contribuindo à consecução dos objetivos organizacionais (HORNGREN, SUNDEN \& STRATTON, 1996). Atkinson et al (2008, p. 81) acrescentam que "[...] um sistema de contabilidade gerencial não pode ser esboçado sem considerar o contexto organizacional no qual ele deve operar e ser usado. Assim, é impossível desenvolver um sistema padrão de contabilidade gerencial para todas as empresas". As considerações dos autores fornecem uma idéia preliminar das expectativas e das responsabilidades que recaem sobre as práticas de contabilidade gerencial, bem como da sua relação com o contexto organizacional.

O Quadro 1 apresenta alguns dos conceitos e objetivos atribuídos à contabilidade gerencial nas últimas décadas. Sua leitura possibilita a visualização de uma pequena parte do processo evolutivo da contabilidade gerencial, fornecendo indícios da constante adaptação às necessidades empresariais ao longo do tempo.

\section{FONTES}

Anthony e Welsch

Anderson, Needles e Cadwell

Hansen e Mowen

Horngren, Foster e Datar (2000)

Louderback et al (2000)

Horngren, Sundem e Stratton

(2004)

\section{CONCEITO / OBJETIVO DA CONTABILIDADE GERENCIAL}

Fornecer informações úteis para os gestores, que são pessoas que estão dentro da organização.

Processo de identificação, mensuração, acumulação, análise, preparação, interpretação e comunicação da informação financeira usada pelos gestores para planejamento, avaliação e controle. A informação financeira possibilita aos gestores, de um lado, o uso apropriado de recursos, de outro lado, a prestação de contas (accountability) decorrente desse uso.

Identificar, coletar, mensurar, classificar, e reportar informações que são úteis para os gestores no planejamento, controle e processo decisório.

Medir e reportar as informações financeiras e não-financeiras que ajudam os gestores a tomar decisões, para atingir os objetivos da organização.

Prover informações para dar apoio às necessidades dos gestores internos da organização.

Processo de identificar, mensurar, acumular, analisar, preparar, interpretar e comunicar informações que auxiliem os gestores a atingir objetivos organizacionais.

Quadro 1: Conceitos e Objetivos da Contabilidade Gerencial

Fonte: Adaptado de Frezatti, Aguiar e Guerreiro (2007) 
O fornecimento de informações aos executivos, gerentes e empregados que trabalham dentro da organização é o foco da contabilidade gerencial (EDMONDS, TSAY \& OLDS, 2008). Assim, para que atinja os objetivos aos quais se propõe, é salutar que a contabilidade gerencial considere as diferenças das necessidades informacionais desses usuários. Adicionalmente, os autores salientam que relatórios de caráter gerencial subsidiam o planejamento empresarial.

Entendem-se como práticas gerenciais contábeis aqueles instrumentos de que a contabilidade gerencial faz uso à consecução dos seus objetivos (SOUZA, LISBOA \& ROCHA, 2003). Comumente, inclusive neste artigo, tais práticas são denominadas artefatos contábeis gerenciais (FREZATTI, 2005; SOUTES, 2006; SOUTES \& GUERREIRO, 2007; ESPEJO, 2008). De acordo com Espejo (2008, p.12) “[...] os artefatos contábeis servem como facilitadores do alcance dos objetivos organizacionais, que a priori baseiam-se na otimização dos recursos, numa perspectiva de resultados de longo prazo". Assim, considerando as exposições realizadas, bem como a manifestação interposta por Lopes (2004, p. 185) de que "[...] ignorar o contexto organizacional é esquecer a própria essência e razão de ser da contabilidade", as próximas seções destinam-se à fundamentação de algumas das abordagens organizacionais e suas inter-relações com a contabilidade gerencial.

\section{ABORDAGENS ORGANIZACIONAIS}

As organizações estabelecem suas atividades diante de um contexto. A forma de estruturação e o processo decisorial, com características próprias inerentes a cada empresa, são respaldados por teorias que constituem a base para a compreensão de tais entidades, explicando o seu modus operandi. A abordagem organizacional, portanto refere-se à perspectiva de análise da organização sob o ponto de vista de uma teoria explicativa. Nesse estudo, o recorte utilizado para consubstanciar o presente ensaio recaise sobre abordagens organizacionais alternativas à perspectiva econômica, ou seja, as abordagens psicológica, contingencial e institucional.

\subsection{ABORDAGEM PSICOLÓGICA}

As teorias psicológicas podem fornecer elementos que contribuam para uma melhor compreensão da concepção humana que está tangenciando as decisões e escolhas realizadas pelos indivíduos em determinadas circunstâncias. Segundo Hall, Lindzey e Campbell (2000, p. 492), um fator-chave que diferencia as várias teorias em psicologia que se tem conhecimento, é a "[...] importância relativa dos determinantes inconscientes do comportamento como oposta à importância dos determinantes conscientes". O Quadro 2 retrata as principais teorias psicológicas que podem respaldar as possíveis investigações referentes a essa temática. 
TEORIA

Teoria Psicanalítica Clássica

Teoria Analítica

Teorias Psicológicas Sociais

Teoria Psicanalítica Contemporânea

Teoria da Personologia

Teoria centrada no indivíduo

Teoria de Traço Fatorial-Analítica

Teoria do Traço Biológico

Teoria do Constructo Pessoal

Teoria Behaviorista ou Comportamental

Teoria do Estímulo-Resposta

Teorias da Aprendizagem Social

Teorias Transpessoais

\section{PRINCIPAIS REPRESENTANTES}

Freud

Jung

Adler, Fromm, Horney e Sullivan

Erikson

Murray

Alport, Rogers, Maslow e Goldstein

Cattell

Eysenck

Kelly

Watson e Skinner

Dollard e Miller

Bandura e Mischel

Wilber, Capra, Grof, Maslow e

Goleman

Quadro 2 - Principais Teorias Psicológicas

Fonte: Adaptado de Hall, Lindzey e Campbell (2000) e Walsh e Vaughan (1980)

Em face da multiplicidade de fatores condicionantes do comportamento humano, no presente ensaio, optou-se por respaldar a discussão proposta por meio da psicologia analítica. Essa delimitação deve-se ao fato de que os preceitos junguianos podem suscitar visões diferenciadas dos processos de escolhas e tomadas de decisões, além de propor os conceitos de inconsciente coletivo e arquétipos que resgatam uma visão antropo-sóciopsicológica dos indivíduos. Ressalta-se que não se tem a aspiração de ignorar as demais teorias psicológicas e nem dar importância diferenciada à teoria junguiana, mas, somente visualizar um outro panorama de estudos que ainda não é tão difundido na contabilidade, tal como a psicologia cognitiva ou o behaviorismo.

A psicologia analítica é uma ramificação da teoria psicanalítica clássica e passa a existir quando Jung discorda dos conceitos pansexualistas de seu mestre Freud. Para Jung, a psique era fluida, multidimensional, viva e capaz de desenvolvimento criativo (YOUNGEISENDRATH \& DAWSON, 2002). Segundo essa corrente psicológica, a personalidade total é formada por diversas estruturas diferenciadas, mas que interagem entre si constantemente. Essas estruturas são: o ego ou mente consciente; o inconsciente pessoal e seus complexos; o inconsciente coletivo e seus arquétipos; as atitudes de introversão e extroversão; as funções do pensamento, do sentimento, da sensação e da intuição e; o centro de toda a personalidade, denominada self (HALL, LINDZEY \& CAMPBELL, 2000). A Figura 1 ilustra de forma simplificada a estrutura da personalidade, de acordo com a psicologia analítica. 


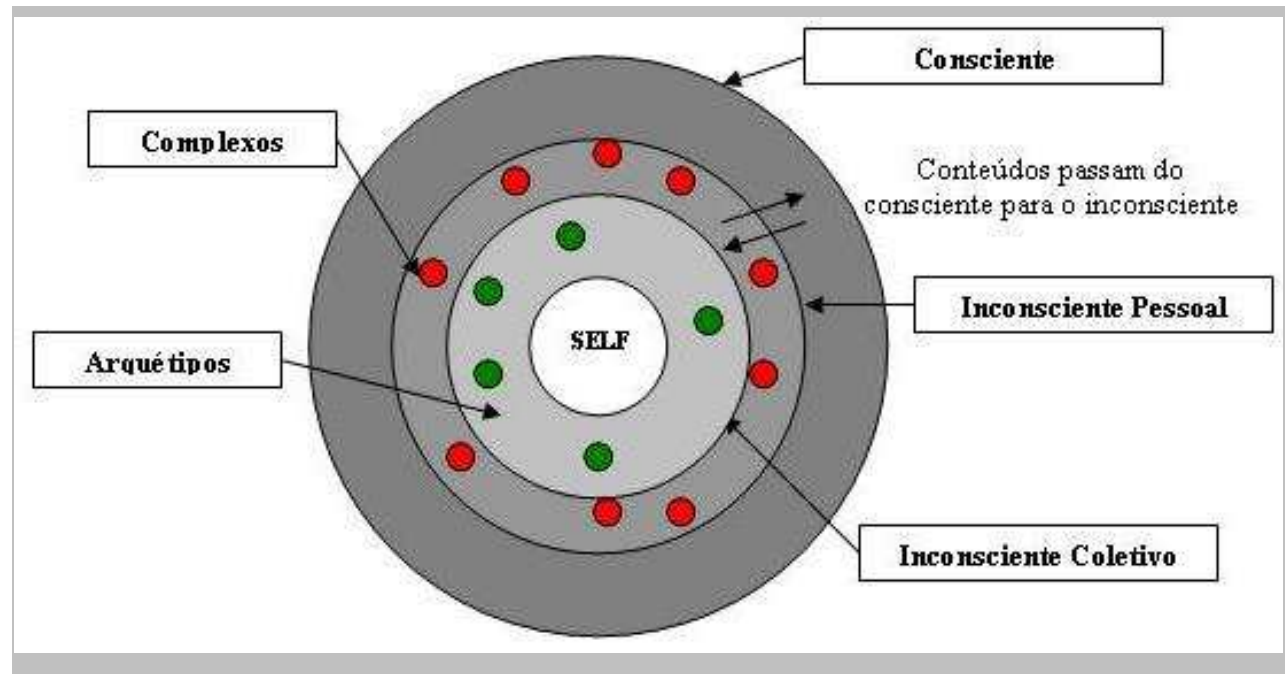

Figura 1: Estrutura da Personalidade

Fonte: Adaptado de Hall, Lindzey e Campbel (2000), Young-Eisendrath e Dawson (2002)

Nesse contexto, pode-se entender por inconsciente pessoal, a região adjacente ao ego (mente consciente), no qual são depositadas as experiências que já foram conscientes, mas que no momento foram esquecidas, reprimidas ou ignoradas. Esses materiais fluem livremente para o ego, coexistindo assim, numa via de mão dupla entre o ego e o inconsciente pessoal. As estruturas que compõem o inconsciente pessoal são chamadas de complexos.

Além do inconsciente pessoal, a teoria analítica menciona o conceito de inconsciente coletivo. De acordo com Guerreiro, Casado e Bio (2004, p.5), “[...] o inconsciente coletivo funciona, na interpretação psicológica, como denominador comum que reúne e explica numerosos fatos impossíveis de entender no momento atual da ciência". Para Hall, Lindzey e Campbell (2000, p. 88), o inconsciente coletivo é “[...] o reservatório de traços de memória latentes herdados do nosso passado ancestral, [...] é o resíduo psíquico do desenvolvimento evolutivo humano, um resíduo que se acumula em conseqüência de repetidas experiências ao longo de muitas gerações". Enquanto as estruturas do inconsciente pessoal são os complexos, aquelas presentes no inconsciente coletivo são denominadas de arquétipos.

Portanto, arquétipos são formas universais de pensamento que contêm uma forte carga de emoção (HALL, LINDZEY \& CAMPBELL, 2000). Complementarmente, Morgan (1996) trata por arquétipos um dos aspectos mais característicos da análise junguiana e que significa em sua essência "modelo original", desempenhando um papel crítico de interligação do indivíduo com seu inconsciente coletivo, perfazendo assim, padrões que estruturam os pensamentos humanos e ordenam o mundo.

Finalmente, conforme ilustrado na Figura 1, o centro de toda a personalidade na psicologia analítica é o self. Jung supôs a existência de um self como sendo o sustentáculo de um processo de individuação, o qual faz com que cada pessoa seja exclusiva em suas atitudes e decisões, ou seja, o ego consciente é parte essencial e o resto é formado pelo inconsciente (YOUNG-EISENDRATH \& DAWSON, 2002). Depreende-se assim, que todas as escolhas e decisões tomadas deveriam atingir o self - um foco central se fosse traçada uma linha imaginária entre a mente consciente e a mente inconsciente; é o ponto de decisão ótima ou de maximização das potencialidades decisórias. 


\subsection{ABORDAGEM CONTINGENCIAL}

A abordagem contingencial é uma vertente das teorias organizacionais que contempla a organização como um sistema aberto, interagindo com o ambiente e outros fatores contingenciais, tais como tecnologia, estrutura, estratégia, entre outros. Tais fatores direcionariam a tomada de decisão, protegendo a organização da incerteza por meio da realização da homeostase, ou seja, o ato de desenvolver sua própria autoregulação, buscando o equilíbrio diante dos fatores influenciadores (STONER \& FREEMAN, 1985).

Morgan (1996) advoga que a abordagem contingencial parte de conceitos da teoria dos sistemas, segundos os quais a organização é entendida como um sistema aberto que influencia e sofre influências do meio. Além do meio externo, a própria organização é composta de subunidades que são subsistemas dinâmicos e sinérgicos. Assim, sob tal abordagem a organização é considerada um organismo vivo (enfoque orgânico).

Em uma perspectiva contingencial, adota-se um componente mais dinâmico ao processo decisório, o ambiente, que interage de forma interdependente com as técnicas administrativas que amparam o processo decisorial do gestor. Enfatiza-se que tal relação apresenta-se repleta de complexidade, pois a variável ambiental é composta de múltiplos fatores para a sua determinação, tais como capacidade preditiva do comportamento do consumidor, número de possíveis fornecedores disponíveis no mercado, escassez de matéria-prima, entre outros fatores.

Nessa relação funcional, a variável ambiente é a independente, sendo que as demais variáveis, técnicas administrativas, são dependentes. "[...] essa relação funcional é do tipo 'se-então' e pode levar a um alcance eficaz dos objetivos da organização" (CHIAVENATO, 1993, p. 802). Tal condição pode atribuir à abordagem contingencial uma característica de promover à empresa um comportamento reativo; no entanto, pesquisadores da área argumentam que é justamente o oposto, pois ao considerar que o ambiente é uma variável importante e influenciadora das práticas organizacionais, o gestor é capaz de analisar a situação específica em que se encontra e escolher o modelo de decisão que melhor se ajuste.

Diante dessa interação, a teoria da contingência preconiza a ausência de unicidade estrutural e organizacional suficientemente efetiva para todas as organizações (DONALDSON, 1999). O autor respalda sua afirmativa salientando a existência de fatores tais como estratégia e tamanho da organização, além da incerteza com relação às tarefas e tecnologias que implicarão variação da estrutura da empresa como um todo. Assim, a organização é contingente a esse conjunto de fatores, os quais Donaldson (1999) denominou de fatores contingenciais. $O$ autor ainda acrescenta que esses fatores refletem a influência do ambiente em que a organização mostra-se inserida, logo, as organizações buscam, continuamente, adaptação a seu ambiente.

Em conformidade com essa linha argumentativa, Espejo (2008) acrescenta que as informações necessárias à tomada de decisão não se restringem àquelas relativas ao ambiente intra-organizacional. A autora enfatiza a importância da concepção sistêmica da organização, remetendo à influência de fatores situacionais tanto externos quanto internos à empresa. No Quadro 2 são apresentados, de forma breve, os primeiros estudos realizados em conformidade com a linha de pensamento da teoria contingencial. 


\begin{abstract}
AUTOR
RESUMO DO ESTUDO
AUTOR
RESUMO DO ESTUDO

Distinguiram a estrutura organizacional de indústrias eletrônicas em duas tipologias - mecanicistas e orgânicas. Estruturas mecânicas são aquelas Burns e verticalmente administradas (alto grau de especialização da tarefa, Stalker hierarquização); mostram-se mais eficientes em ambientes estáveis. Em (1961) sentido oposto, estruturas orgânicas são aquelas mais horizontalizadas (delegação de tarefas, controles informais, baixos níveis de especialização da tarefa), características de ambientes instáveis.

Defendeu a tese que a estrutura decorre da estratégia adotada pela organização, contribuindo à compreensão dos modelos de gestão Chandler contemporâneos. Esclareceu que diferentes espécies de estruturas (1962) organizacionais foram necessárias para suportar estratégias e ambientes distintos, enfatizando 0 ambiente como condicionante da estrutura organizacional.

Incluiu a variável tecnologia numa análise comparativa de 100 empresas de diferentes tipos, demonstrando a existência de três tipos de organização: produção unitária ou oficina, produção em massa ou mecanizada e produção

Joan

Woodward

(1965)

Lawrence

e Lorsch

(1967) em processo ou automatizada. As tipologias mostraram-se dependentes do grau de envolvimento de recursos tecnológicos em virtude da estrutura e das estratégias norteadoras dos negócios. Observou que a estrutura organizacional não tem seu relacionamento limitado ao porte, mas, sobretudo à tecnologia.

Foram os precursores do uso da expressão "teoria da contingência". Atentaram à capacidade que o homem e a organização têm de modificar suas próprias estruturas e/ou estratégias como alternativa à adaptação ambiental.

Quadro 2 - Precursores da Abordagem Contingencial Fonte: Adaptado de Espejo (2008)

Ao discorrer acerca do estudo realizado por Lawrence e Lorsch, Morgan (2006), destaca a importância de suas principais idéias - diferenciação e integração. Segundo o autor, a investigação desses dois pesquisadores britânicos aprimorou o enfoque contingencial, mostrando-se bastante contributiva, à medida que expôs a necessidade de variação de estilos organizacionais entre suas subunidades em função de determinadas características de seus respectivos sub-ambientes.
\end{abstract}

\title{
3.3 ABORDAGEM INSTITUCIONAL
}

A teoria institucional pode ser visualizada como uma espécie de continuação e extensão da revolução intelectual que, a partir de meados dos anos 60, introduziu concepções de sistemas abertos nos estudos organizacionais (SCOTT, 2008). Em linhas gerais, as discussões relativas à teoria institucional das organizações desenvolveram-se sob a égide de três orientações com diferentes origens e raízes filosóficas: [1] nova sociologia institucional (NIS - New Institutional Sociology), [2] nova economia institucional (NIE - New Institutional Economics) e [3] velha economia institucional (OIE - Old Institutional Economics). Segundo Burns e Scapens (2000), os estudos analíticos de mudanças nas rotinas dos sistemas de contabilidade gerencial têm respaldo junto à velha economia institucional (voltada prioritariamente para o estudo das micro-instituições das 
organizações) e à nova sociologia institucional (focada em questões macro-institucionais de ordens econômica, política e social).

No tocante à NIS, a característica fundamental da orientação econômica é representada pela tentativa de "inserir o processo econômico no marco de uma construção social manipulada pelas forças históricas e culturais" (CARVALHO \& VIEIRA, 2003), corroborando para que as transações representem o elemento central de análise. Ainda em conformidade com Carvalho e Vieira (2003), as discussões ancoradas na ciência política concentram seus interesses em questões como a autonomia relativa de instituições políticas em relação à sociedade, a complexidade dos sistemas políticos, além da representação e do simbolismo no universo político. Scott (2008) advoga que os sociólogos têm dispensado maior atenção às instituições do que os economistas e os cientistas políticos. De acordo com o autor, numa orientação sociológica há uma constante busca pelo refinamento de idéias de uma variedade de antecessores, contribuindo para a continuidade, mudança e progressos discursivos.

A inserção da abordagem institucional nos estudos organizacionais teve início a partir da década de 50, com Philip Selznick (CARVALHO \& VIEIRA, 2003). Selznick (1957) identificou a capacidade de agência da liderança no plano interno da organização, definindo instituição como um organismo adaptável e receptivo; uma espécie de produto naturalmente decorrente das pressões e necessidades sociais. Assim, uma vez que o foco de análise de Selznick (1957) é a organização, é possível afirmar que a definiçãa de institucionalização do autor dá-se numa dimensão local e política (os grupos estão em constante interação), articuladamente organizada para defender seus interesses. Nesse sentido, para Selznick (1957) a institucionalização está fortemente ligada à infusão de valores.

Para Meyer e Rowan (1977) o surgimento de estruturas organizacionais formais decorre da incorporação e apego em práticas e procedimentos que prevalecem na organização, independentemente da eficácia proveniente de sua adoção. Nesse sentido, numa lógica cultural cognitiva, as organizações adotam cerimonialmente mitos sociais. Apoiados nessa lógica, Meyer e Rowan (1977) atentam para uma dimensão mais cultural, ressaltando que a racionalidade não é plena, face às limitações cognitivas condicionadas pelas crenças e valores que limitam as escolhas de toda uma sociedade. Partindo do pressuposto que os atores e seus respectivos interesses são institucionalmente construídos, DiMaggio e Powell (1983) reúnem elementos com uma tentativa de prover explicações à homogeneidade de formas e práticas organizacionais. Assim, a obra dos autores introduz uma nova unidade de análise, que contribuiu para distinção entre campo e ambiente.

A exploração de uma diversidade de pontes entre as vertentes institucionais conduziu ao prolongamento das discussões sob o enfoque de duas modelagens - o velho e o novo institucionalismo. A ação é o foco no velho institucionalismo; a preocupação dessa corrente discursiva é como a organização trabalha a lógica de interesse e de racionalidade, ou seja, como os gestores dirigem e reagem às pressões ambientais, considerando aspectos culturais. No novo institucionalismo, cujo desenvolvimento deu-se na década de 70 (PALMER, BIGGART \& DICK, 2008), tem-se um deslocamento do nível societário rumo ao nível de campo; o foco é a estrutura. A adoção de mitos cerimoniais por parte das organizações ilustra um movimento de fora para dentro da organização, coadunando, com isso, no caráter estrutural. 0 Quadro 4 reúne um sumário das principais características do velho e do novo institucionalismo. 
DIMENSÃO

\begin{tabular}{|c|c|c|}
\hline & VELHO & Novo \\
\hline Conflitos de Interesse & Central & Periférico \\
\hline Fonte de Inércia & Interesses adquiridos & Legitimidade ambiental \\
\hline Nível de Análise & Organizações focais & Campo, setor, sociedade \\
\hline Lugar Institucional & $\begin{array}{l}\text { Valores organizacionais, } \\
\text { cultura }\end{array}$ & Resumido, de sociedade \\
\hline $\begin{array}{l}\text { Ênfase de } \\
\text { Comportamento }\end{array}$ & Compromisso & Hábitos, papéis \\
\hline Dinâmica Organizacional & Mudança & Persistência \\
\hline $\begin{array}{l}\text { Formas Chave de } \\
\text { Cognição }\end{array}$ & Valores, normas, atitudes, & $\begin{array}{l}\text { Classificações, manuscritos, } \\
\text { esquemas }\end{array}$ \\
\hline Psicologia Social & Socialização & Atribuição \\
\hline Metas & Negociável & Simbólico \\
\hline Ênfase Estrutural & Redes informais & Administração formal \\
\hline
\end{tabular}

Scott (2008) argumenta que as instituições representam estruturas sociais multifacetadas, constituídas de elementos simbólicos, atividades sociais e recursos materiais. $\mathrm{O}$ autor destaca a existência de três elementos fundamentais à constituição das instituições - reguladores, normativos e cultural-cognitivos. 0 pilar regulador está relacionado à imposição de regras, leis e sanções; o pilar normativo abarca aspectos ligados à certificação e aceitação de valores (aquilo que é preferido/desejável), de modo que o sistema normativo autoriza e habilita a ação social ao mesmo tempo em que impõe constrangimento ao comportamento social; por fim, o pilar cultural-cognitivo baseia-se na existência de um fluxo contínuo de acontecimentos alavancados pela atribuição de significados a objetos e atividades e pela interação de significados que os mantêm e os transforma. Machado-da-Silva, Fonseca e Crubellate (2005) argumentam que legitimidade é palavra-chave no contexto institucional, pois representa o elemento que permite a manutenção ou mudança da instituição, visto que questionamentos a respeito da adequação de práticas, normas e procedimentos podem impedir a reprodução dos padrões institucionalizados, culminando no desencadeamento de um processo de desinstitucionalização, seguido da relegitimação de novos significados e ações, típicos de um processo de reinstitucionalização. 


\section{CONTABILIDADE GERENCIAL E AS ABORDAGENS TEÓRICAS ORGANIZACIONAIS}

Face à amplitude do tema proposto nessa investigação optou-se, inicialmente, pela realização de uma breve revisão literária acerca da contabilidade gerencial e das abordagens organizacionais escopo do presente ensaio. A seguir, explicitam-se pesquisas nacionais e internacionais da ciência contábil respaldadas pelas abordagens psicológica, contingencial e institucional.

\subsection{A CONTABILIDADE GERENCIAL SOB UMA ABORDAGEM DA PSICOLOGIA ANALÍTICA}

Apesar de se optar por relacionar a psicologia analítica com a contabilidade gerencial por motivos anteriormente citados, não se pode desprezar que pesquisas organizacionais têm sido realizadas utilizando-se de conceitos próprios da psicologia no entendimento do comportamento humano. Estudos internacionais têm sido realizados com base nos estilos cognitivos para explicar o processo de tomada de decisão (ALLINSON \& HAYES, 1996; GARDNER \& MARTINKO, 1996; CHENG, LUCKETT \& SCHULZ, 2003; HOUGH \& OGILVIE, 2005; GALLÉN, 2006; HALL, 2008). No Brasil percebe-se que essa interação entre a psicologia e a contabilidade gerencial ainda é pouco explorada, com escassos estudos referenciados (GUERREIRO, CASADO \& BIO, 2004; GUERREIRO, FREZATTI e CASADO, 2006; SANTOS, ALMEIDA e CROZATTI, 2007).

A operacionalização, o planejamento, a execução e o controle da contabilidade gerencial mostram-se intimamente relacionados e dependentes do fator humano, estando, assim, sob influências comportamentais que podem interferir nas escolhas das práticas gerenciais a serem utilizadas para consubstanciar o processo decisório. Nem sempre é possível explicar a utilização de um artefato contábil em detrimento de outro exclusivamente por meio da racionalidade econômica, tendo em vista a concorrência de fatores, conscientes e inconscientes, intermitentes na percepção do gestor (GUERREIRO, FREZATTI \& CASADO, 2006).

Nesse contexto, utilizando-se dos fundamentos próprios da psicologia analítica, pode-se firmar um conceito de inconsciente coletivo em contabilidade gerencial. Apesar de Jung conceber a idéia de arquétipo como sendo universal e aceita por toda a espécie humana, em determinados agrupamentos ou equipes verificam-se a presença de formaspensamento que formam um inconsciente coletivo daquele determinado grupo. Para Guerreiro, Casado e Bio (2004), freqüentemente observam-se fatores inconscientes atuantes nas atividades empresariais, como por exemplo, quando se questiona o porquê de determinadas atividades serem feitas daquela forma específica e a resposta é "sempre fizemos assim".

No ambiente da contabilidade gerencial percebe-se que muitas vezes, os profissionais agem de forma mecanicista e repetitiva, pois um conjunto de hábitos e rotinas está legitimado em suas atividades cotidianas (internalizados), formando uma base cultural sólida e difícil de ser modificada. Esse processo pode ser entendido por meio da psicologia analítica, visto que, essa cultura predominante se forma devido à presença de arquétipos que se tornam profundamente arraigados no contexto organizacional formando um inconsciente coletivo, no qual todos agem dentro de uma conduta equânime. Corroborando com essa idéia, Maturana (2001, p.121), desvela que, “[...] somos biologicamente o espaço psíquico e espiritual que vivemos, seja como membros de uma cultura ou como resultado de nosso viver individual na reflexão que, inevitavelmente, nos transforma porque transforma nosso espaço relacional". Nesse sentido, é provável que as 
pessoas pertencentes a uma determinada equipe estejam imbricadas em "prisões psíquicas", representadas pelo ambiente empresarial, que as condicionam, uma vez que thes são exigidos comportamentos mecanicistas e repetitivos como se não fossem dotados de raciocínio. Dessa maneira, deve-se enfatizar que organizações são diferentes umas das outras e, portanto, cada qual possui um self próprio a ser determinado pelas pessoas que as constituem e pelos padrões arquetípicos que as definem.

Outro fator a ser observado em contabilidade gerencial é o de que não há um modelo pré-estabelecido de artefatos contábeis gerenciais, passível de aplicação indistinta, ou seja, essas técnicas devem ser colocadas em prova e analisadas de acordo com as necessidades informacionais de cada entidade. Portanto, se determinado artefato for utilizado sem análise crítica, poderá trazer custos elevados à empresa, por produzir informações desnecessárias e; em contraposição a esse fato, a ausência de reflexão e análise pode tornar a utilização do arcabouço contábil gerencial mecânica, repetitiva e condicionada pelos arquétipos organizacionais existentes na entidade.

\subsection{A CONTABILIDADE GERENCIAL SOB UMA ABORDAGEM CONTINGENCIAL}

Devido à sua importância analítica em relação à tomada de decisão, os estudiosos da contabilidade têm voltado sua atenção para a abordagem contingencial, pois apesar do desenvolvimento e utilização de técnicas contábeis sofisticadas, não há garantia de sucesso organizacional por meio da aplicação universal dessa ou daquela técnica em particular, pressupondo que há uma série de fatores a serem considerados para alcançar eficiência e eficácia (HALDMA \& LÄÄTS, 2002, SHARMA, 2002; CHENHALL, 2003; HANSEN \& VAN DER STEEDE, 2004; TILLEMA, 2005; ESPEJO, 2008).

Haldma e Lääts (2002), por exemplo, realizaram uma pesquisa baseada nas mudanças políticas e estruturais que a Estônia sofreu na década de 90, principalmente por ter obtido sua independência em 1991. Seu objetivo, portanto, era identificar as práticas de contabilidade gerencial das empresas industriais estonianas, explorando os principais impactos das mesmas em uma perspectiva teórica contingencial.

O estudo de Sharma (2002) concentrou-se em analisar os efeitos das variáveis contingenciais nas características orçamentárias, baseando-se no pressuposto de que

\section{[...] algumas das características do sistema orçamentário de empresas orientadas administrativamente por controles, incluem: (i) uso extensivo de orçamentos como um mecanismo de comunicação [...], (ii) uso extensivo de orçamentos para avaliação de desempenho [...]; (iii) uso extensivo de orçamentos como mecanismos de controle [...]. Em contraste, empresas menores tendem a implementar sistemas onde os mecanismos de controle, coordenação e comunicação são mais informais e pessoais.( SHARMA, 2002, p. 105)}

Já Chenhall (2003) realizou uma revisão crítica sobre os estudos baseados na teoria da contingência nos 20 anos anteriores a sua publicação. Ele ressalta que convencionalmente, a perspectiva contingencial parte do pressuposto de que os sistemas de controle gerenciais - SCG são ferramentas que auxiliam os gestores na tomada de decisão, sendo influenciados pelo contexto em que operam. Segundo o autor, essa visão parece delegar ao SCG um comportamento integrativo diante de outras variáveis no que tange à decisão propriamente dita.

A pesquisa realizada por Hansen e Van der Stede (2004) buscou investigar quatro motivos essenciais pelos quais as empresas adotam o orçamento, seus antecedentes e outras características orçamentárias que potencialmente influenciam o desempenho orçamentário de acordo com as razões indicadas. 
A pesquisa de Tillema (2005) também é um exemplo de aplicação da teoria contingencial em pesquisas contábeis. Por meio de estudos de caso em profundidade em duas companhias de gás e energia, emitiu suas conclusões baseando-se no dinamismo ambiental. 0 autor relata que as consequiências financeiras de uma organização ou subunidade que reage a alterações no ambiente externo são difíceis de prever, pois essas mudam rapidamente a natureza e o porte de suas atividades para se adaptar à turbulência ambiental. A base argumentativa dos autores que defendem a corrente teórica contingencial é o fato de variáveis situacionais afetarem a organização, influenciando a utilização de artefatos contábeis.

No Brasil, um exemplo de aplicação da teoria contingencial nos estudos contábeis por meio de uma pesquisa de natureza empírica, é a de Espejo (2008). Tal investigação constatou a influência (direta e indireta) de fatores contingenciais internos e externos na adoção do orçamento empresarial em indústrias paranaenses. A relação comprovada pela autora baseou-se nas variáveis ambiente, estrutura, estratégia, tecnologia e porte organizacional e o sistema orçamentário, modelada por equações estruturais.

Contrapondo-se à teoria contingencial, advoga-se, também, a existência de "seleção natural" do ambiente, chamada de ecologia populacional, baseando-se na teoria darwiniana. Essa teoria tem sido criticada por sua visão anti-management, destituindo o poder do administrador, retirando-lhe o livre-arbítrio de estabelecer suas próprias estratégias e não o responsabilizando pelo sucesso/fracasso organizacional. Segundo esta teoria, o ambiente é determinante (HREBINIAK \& JOYCE, 1985). Exploradas as principais características da abordagem contingencial, a seção seguinte destina-se a exposição da possibilidade de relação entre a contabilidade gerencial e os fatores institucionais nas organizações.

\subsection{A CONTABILIDADE GERENCIAL SOB UMA ABORDAGEM INSTITUCIONAL}

O desenvolvimento de estudos relativos aos direcionamentos contábeis, focados na compreensão do surgimento e da legitimação das estruturas sociais e de significados, tem contribuído à orientação das atividades profissionais (LOUNSBURY, 2008). Em conformidade com a linha argumentativa de Lounsbury (2008), inúmeros estudos que se propõem a analisar aspectos relativos à contabilidade gerencial, têm recorrido à teoria institucional para construção do quadro teórico de referência (HOPWOOD \& MILLER, 1994; BURNS \& SCAPENS, 2000; GUERREIRO, PEREIRA \& LOPES, 2004; GUERREIRO et al, 2005; BRANCO, 2006; ZAN, 2006; OYADOMARI et al, 2008; VOLLMER, 2009).

Branco (2006) expõe que a compreensão da contabilidade e de seu papel social demanda estudos orientados por uma abordagem condutora à percepção da maneira como os agentes elaboram suas representações da realidade, oportunidades com as quais se defrontam e suas regras de decisão. $O$ autor ainda expõe que além de governar as formas habituais de comunicação e interação social, a contabilidade também governa a percepção da realidade e a elaboração do conhecimento sobre tal realidade, podendo ser visualizada como um instrumento de conhecimento e comunicação. De forma similar, Miller (1994) argumenta que uma visão emergente da contabilidade diz respeito à sua visualização como uma prática de ordem social e institucional, capaz de influenciar entidades e processos de modo a transformá-los à obtenção de fins específicos. 0 autor ainda acrescenta que, à luz dessa perspectiva, a utilidade da contabilidade não se restringe à evidenciação de fatos da atividade econômica, uma vez que é uma prática social.

Orientações puramente racionalistas tendem a negligenciar dimensões sócioculturais, comprometendo a compreensão das transformações do mundo moderno (Carvalho e Vieira, 2003). De modo similar, Guerreiro et al (2005) expõem que a contabilidade gerencial deve ser visualizada como um produto de hábitos e rotinas 
institucionalizados na empresa para dar coerência e significado ao comportamento da organização. Assim, a entendimento da intenção e, consequentemente, do significado imbricado em cada ação de natureza contábil tende a conferir legitimidade e significação à prática contábil em sua amplitude.

Reconhecendo a importância da compreensão do contexto no âmbito extraorganizacional, Burns e Scapens (2000) desenvolveram um estudo focado na contextualização da mudança da contabilidade gerencial na esfera intra-organizacional. Nessa pesquisa, os autores atentam à contabilidade gerencial como um meio que estabelece regras (projeções formais de procedimentos) e rotinas (procedimentos em uso) que são codificadas, compreendidas, reproduzidas, internalizadas pelos colaboradores da instituição e manifestadas na cultura e no clima organizacional.

Com base nas argumentações expostas, depreende-se que a institucionalização de práticas organizacionais não só representa como também decorre de um comportamento, seja de cunho empresarial ou humano. Assim, ratifica-se o incentivo interposto por Machado-da-Silva, Fonseca e Crubellate (2005) à exploração da interface da teoria institucional com outras vertentes de análise das organizações.

\section{UTILIZAÇÃO DE ARTEFATOS DE CONTABILIDADE GERENCIAL E ABORDAGENS ORGANIZACIONAIS: UMA CONVERSAÇÃO NECESSÁRIA}

A presente reflexão foi realizada com a finalidade de verificar se a compreensão da utilização dos artefatos de contabilidade gerencial pode ser facilitada por meio da criação de um elo com as abordagens organizacionais. Trata-se de um ensaio teórico que propõe uma análise crítico-reflexiva acerca da questão pesquisada. Nesse sentido, considerando a discussão posta à reflexão e a base conceitual das teorias organizacionais abordadas, ressalta-se a importância da conversação com outras áreas do conhecimento. A teoria organizacional contribui no processo de análise e diagnóstico de problemas, tanto no fornecimento de ferramentas para explicar eventuais declínios, como na implantação de mudanças para manter a companhia competitiva e reverter situações difíceis (DAFT, 2008). Complementarmente, Guerreiro et al (2005) salientam que as empresas não utilizam novas abordagens à contabilidade gerencial porque os novos conceitos ainda não tiveram seus processos de institucionalização efetivados, corroborando à ausência de pilares de sustentação para que tais conceitos convertam-se em hábitos organizacionais de modo a constituir a base das rotinas e das instituições.

As proposições de Daft (2008) e Guerreiro et al (2005), associadamente às pesquisas referenciadas no presente ensaio que remetam à conexão entre a contabilidade gerencial e as abordagens organizacionais, denotam o seu potencial contributivo à promoção de uma melhor compreensão no processo de utilização dos artefatos contábeis gerenciais.

No tocante à abordagem psicológica, a discussão realizada sugere que a compreensão, por parte do tomador de decisão, da importância da utilização do ferramental representado pela contabilidade no processo de maximização do valor das empresas deve ser transferida para o nível da consciência. Em adição, expõe-se a necessidade de que, após tal transferência, sejam planejadas ações que subsidiem uma sadia criação de novos hábitos e rotinas, gerando assim novo inconsciente coletivo, para que artefatos de contabilidade gerencial alternativos possam integrar o rol de práticas contábeis.

Quanto à abordagem contingencial, a reflexão suscitada na presente discussão remete à necessidade de, além da investigação de fatores contingenciais isolados e sua 
influência na adoção dos artefatos contábeis, encontrar-se a combinação entre fatores contingenciais (ambientes, tecnologia, estratégia, estrutura, porte, estilo gerencial, entre outros) e os artefatos contábeis gerenciais que representem o melhor encaixe e consequentemente contribuam a um desempenho superior. Tal assertiva significa uma aproximação cada vez maior do profissional contábil com a gestão organizacional.

Com relação à abordagem institucional, é possível depreender que a ampliação do diálogo da contabilidade gerencial com a teoria institucional como um todo, pode conduzir a uma melhor compreensão desta logicidade procedimental, auxiliando na promoção de explicações para a adoção dos artefatos dessa ramificação contábil. Adicionalmente, ressalta-se que compreender a lógica de condução de um tema permite identificar em qual direção o pensamento está se desenvolvendo. Nesse sentido, a realização de pontes entre os resultados dessa natureza e as principais acepções epistemológicas auxilia no processo de construção de conhecimento sobre a prática contábil e não para a prática da contabilidade.

À guisa de conclusão, salienta-se que a presente discussão possui implicações de naturezas acadêmicas e profissionais. No âmbito acadêmico, verifica-se que a conversação entre a contabilidade gerencial e outras áreas do conhecimento, especialmente com base nas abordagens organizacionais selecionadas para esse ensaio, expõe uma ótica alternativa à racionalidade econômica, estimulando assim, conexões multidisciplinares com outras ciências. Profissionalmente, a reflexão interposta sugere que o contador, no exercício de seu ofício, aproxime-se cada vez mais do gestor em termos de equiparação de responsabilidade e reconhecimento profissional. Isso se deve em virtude da complexidade que permeia o tratamento da contabilidade gerencial. Adicionalmente, vislumbra-se a necessidade do contador possuir habilidades relacionadas à gestão, sendo que no seu currículo acadêmico devem ser contempladas disciplinas tais como psicologia, comportamento organizacional, cultura organizacional, estratégias empresariais, entre outras, que permitam o desenvolvimento de habilidades analíticas.

Reconhece-se, diante do exposto, que futuras pesquisas relacionadas à contabilidade gerencial necessitam considerar uma integração entre as abordagens organizacionais supracitadas. Apesar do incremento da complexidade investigativa que tal sugestão contempla, o conhecimento proveniente de tais cuidados epistemológicos não seria fragmentado e representaria expressiva evolução à ciência contábil. À luz dessas considerações, evidencia-se uma proposta de quebra de paradigma, orientada para uma visão mais ampla da pesquisa contábil que venha a contribuir sobremaneira à inserção da pesquisa brasileira no cenário internacional e a um profícuo alinhamento entre as necessidades empresarias e os objetivos da contabilidade gerencial.

\section{REFERÊNCIAS}

ALLINSON, C. W.; HAYES, J. The Cognitive Style Index: A Measure of Intuition-Analysis for Organizational Research. Journal of Management Studies. v. 33, n. 1, p. 119-135, Jan. 1996.

ATKINSON, A. A.; BANKER, R. D.; KAPLAN, R. S.; YOUNG, S. M. Contabilidade Gerencial. 2.ed. São Paulo: Atlas, 2008.

BRANCO, M. C. Uma Abordagem Institucionalista da Contabilidade. Revista Contabilidade \& Finanças. São Paulo, v. 17, n. 42, pp. 104-112, Set./Dez. 2006.

BURNS, J.; SCAPENS, R. W. Conceptualizing Management Accounting Change: An Institutional Framework. Management Accounting Research. v. 11, p. 3-25. Mar. 2000. 
CARVALHO, C. A.; VIEIRA, M. M. F. Contribuiçõoes da Perspectiva Institucional para Análise das Organizações: Possibilidades Teóricas, Empíricas e de Aplicação. In: CARVALHO, Cristina Amélia; VIEIRA, Marcelo Milano Falcão. Organizações, Cultura e Desenvolvimento Local: a Agenda de Pesquisa do Observatório da Realidade Organizacional. Recife: EDUFEPE, 2003.

CHENG, M. M.; LUCKETT, P. F.; SCHULZ, A. K-D. The Effects of Cognitive Style Diversity on Decision-Making Dyads: An Empirical Analysis in the Context of a Complex Task. Behavioral Research In Accounting. v. 15, p. 39-62, 2003.

CHENHALL, R. H. Management control systems design within its organizational context: findings from contingency-based research and directions for the future. Accounting, Organizations and Society, 28, p. 127-168, 2003.

CHIAVENATO, I. Introdução à Teoria Geral da Administração. 4.ed. São Paulo: Makron Books, 1993.

DAFT, R. L. Organizações: Teoria e Projetos. 2.ed. São Paulo: Cengage Learning, 2008.

DIMAGGIO, P. J.; POWELL, W. W. Introduction. In: POWEL, W. W; DIMAGGIO, P. J. The New Institutionalism in Organizational Analysis. London: Sage Publications, 1991. p. 138.

DIMAGGIO, P. J.; POWELL, W. W. The Iron Cage Revisited: Institutional Isomorphism and Collective Rationality in Organizational Fields. American Sociological Review. v. 48, n. 2. Apr. 1983. p. 147-160.

DONALDSON, L. Teoria da Contingência Estrutural. In: CLEGG, Stewart R.; HARDY, Cynthia; NORD, Walter R. Handbook de Estudos Organizacionais. v. 1. São Paulo: Atlas, 1999. p. 104-131.

EDMONDS, T. P.; TSAY, B-Y.; OLDS, P. R.; Fundamental Managerial Accounting Concepts (Hardcover). 4.ed. New York: McGraw Hill Irwin, 2008.

ESPEJO, M. M. dos S. B. Perfil dos Atributos do Sistema Orçamentário sob a Perspectiva Contingencial: uma Abordagem Multivariada. São Paulo, 2008. Tese (Doutorado em Ciências Contábeis) - Programa de Pós-Graduação em Ciências Contábeis, Faculdade de Economia, Administração e Contabilidade da Universidade de São Paulo, São Paulo.

FREZATTI, F. Management Accounting Profile of Firms Located in Brazil: a Field Study. Brazilian Administration Review. Curitiba. v. 2, n. 1, p. 73-87, Jan./Jun. 2005.

FREZATTI, F.; AGUIAR, A. B. de; GUERREIRO, R. Diferenciações entre a Contabilidade Financeira e a Contabilidade Gerencial: Uma Pesquisa Empírica a partir de Pesquisadores de Vários Países. Revista Contabilidade \& Finanças - RCF. São Paulo. n. 33, p. 9-22, Mai. /Ago. 2007.

GALLÉN, T. Managers and strategic decisions: does the cognitive style matter? Journal of Management Development. V. 25, n.2, p. 118-133, 2006.

GARDNER, W. L.; MARTINKO, M. J. Using the Myers-Briggs Type Indicator to study managers: a literature review and research agenda. Journal of Management. v. 22, n.1, p. 45-83, 1996.

GUERREIRO, R.; CASADO, T.; BIO, S. R. Some reflections on the archetypes in cost accounting: na exploratory study. Journal of Applied Management Accounting Research. v. 2, n.1, p. 41-54, 2004. 
GUERREIRO, R.; FREZATTI, F.; CASADO, T. Em Busca de um Melhor Entendimento da Contabilidade Gerencial - Conceitos da Psicologia, Cultura Organizacional e Teoria Institucional. Revista Contabilidade \& Finanças - RCF. São Paulo: Edição Comemorativa. p. 7-21, Set. 2006.

GUERREIRO, R.; FREZATTI, F.; LOPES, A. B.; PEREIRA, C. A. O Entendimento da Contabilidade Gerencial sob a Ótica da Teoria Institucional. Revista Organizações \& Sociedade - O\&S. v. 12., n. 35., p. 91-106., Out./Dez. 2005.

GUERREIRO, R.; PEREIRA, C. A.; LOPES, A. B.. Uma Contribuição ao Entendimento da Estabilidade e da Mudança da Contabilidade Gerencial sob a Ótica da Teoria Institucional. In: XXVIII EnANPAD, 2004, Curitiba. Anais do XXVIII EnANPAD. Paraná, EnANPAD, 2004. CD-ROM.

HALDMA, T. \& LÄÄTS, K. Contingencies influencing the management accounting practices of Estonian manufacturing companies. Management Accounting Research, vol. 13, pp. 379-400, 2002.

HALL, C. S., LINDZEY, G.; CAMPBELL, J. B. Teorias da Personalidade. 4. ed. Porto Alegre: Artmed, 2000.

HALL, M. The Effect of comprehensive performance measurement systems on role clarity, psychological empowerment and managerial performance. Accounting, Organizations and Society. v. 33, p.141-163, 2008.

HANSEN, S. C. \& VAN DER STEDE, W. A. Multiple facets of budgeting: an exploratory análisis. Management Accounting Research, v. 15, p. 415 - 439, 2004.

HOPWOOD, A. G.; MILLER, P. Accounting as Social and Institutional Practice. Cambridge: Cambridge Studies in Management, 1994.

HORNGREN, C. T.; SUNDEM, G. L.; STRATTON, W. O. Introduction to Management Accounting. 10. ed. Prentice Hall: Upper Saddle River, 1996.

HOUGH, J. R.; OGILVIE, Dt. An Empirical Test of Cognitive Style and Strategic Decision Outcomes. Journal of Management Studies. v. 42, n. 2, p. 417.

HREBINIAK, L. G.; JOYCE, W. F. Organizational Adaptation: Strategic Choice and Environmental Determinism. Administrative Science Quarterly. v. 30, p.336-349, 1985.

ITTNER, C. D.; LARCKER, D. F. Empirical Managerial Accounting Research: Are We Just Describing Management Consulting Practice? The European Accounting Review. v. 11, n. 3, p. 787-793. Out. 2002.

LOPES, A. B. A Teoria dos Contratos, Governança Corporativa e Contabilidade. In: LOPES, Alexsandro Broedel; IUDÍCIBUS, Sérgio de. Teoria Avançada da Contabilidade. São Paulo: Atlas, 2004.

LOUNSBURY, M. Institutional Rationality and practice Variation: New Directions in The Institutional Analysis of Practice. Accounting, Organizations and Society. v. 33, p. 339362, 2008.

MACHADO-DA-SILVA, C. L.; FONSECA, V. S. da; CRUBELLATE, J. M. Estrutura, Agência e Interpretação: Elementos para uma Abordagem Recursiva do Processo de Institucionalização. Revista de Administração Contemporânea - RAC. v. 1, p. 09-39, 2005.

MATURANA, H. A Ontologia da Realidade. Belo Horizonte: Editora UFMG, 2001.

MEYER, J. W.; ROWAN, B. Institutionalized Organizations: Formal Structure as Myth and Ceremony. The American Journal of Sociology. v. 83, n. 2, p. 330-363. Sep. 1977. 
MILLER, P. Accounting as Social and Institutional Practice: an Introduction. In: HOPWOOD, Anthony G; MILLER, Peter. Accounting as Social and Institutional Practice. Cambridge: Cambridge Studies in Management, 1994, pp. 1-39.

MORGAN, G. Imagens da Organização. São Paulo: Altas, 1996.

OYADOMARI, J. C. T.; CARDOSO, R. L.; MENDONÇA, O. R.; LIMA, M. P.. Fatores que influenciam a adoção de Artefatos de Controle Gerencial nas Empresas Brasileiras. Um Estudo Exploratório sob a ótica da Teoria Neo-Institucional. In: $8^{\circ}$ Congresso USP de Controladoria e Contabilidade, 2008, São Paulo. Anais do $8^{\circ}$ Congresso USP de Controladoria e Contabilidade. São Paulo.

PALMER, D.; BIGGART, N.; DICK, B. Is the New Institutionalism a Theory? In: GREENWOOD, Royston; OLIVER, Christine; SAHLIN-ANDERSSON, Kerstin; SUDDABY, Roy. The Sage Handbook of Organizational Institutionalism. London: Sage Publications, 2008, p. 739768.

REIS, L. G. dos; PEREIRA, C. A. Uma Análise das Contribuições das Teorias Organizacionais para o Estudo da Contabilidade Gerencial. In: $7^{\circ}$ Congresso USP de Controladoria e Contabilidade, 2007, São Paulo. Anais do $7^{\circ}$ Congresso USP de Controladoria e Contabilidade. São Paulo.

SANTOS, A. R. dos; ALMEIDA, L. B. de; CROZATTI, J. Considerações sobre o Processo de Institucionalização de Área Organizacional de Controladoria: Uma Abordagem de Interação da Visão da Psicologia Humana, Cultura Organizacional à Teoria Institucional. In: XXXI EnANPAD, 2007, Rio de Janeiro. Anais do XXXI EnANPAD. Rio de Janeiro, EnANPAD, 2007. CD-ROM.

SCOTT, R. W. Institutions and Organizations - Ideas and Interests. 3.ed. Thousand Oaks: Sage, 2008.

SELZNICK, P. A Liderança na Administração: Uma Interpretação Sociológica. Rio de Janeiro: Fundação Getúlio Vargas, 1957.

SHARMA, D. S. The differential effect on environmental dimensionality, size and structure on budget system characteristics in hotels. Management Accounting Research, 13, pp. 101-130, 2002.

SOUTES, D. O. Uma Investigação do Uso de Artefatos da Contabilidade Gerencial por Empresas Brasileiras. São Paulo, 2006. Dissertação (Mestrado em Contabilidade) Faculdade de Economia e Administração, Universidade de São Paulo, São Paulo.

SOUTES, D. O.; DE ZEN, M. J. de C. M. Estágios Evolutivos da Contabilidade Gerencial em Empresas Brasileiras. São Paulo. In: $5^{\circ}$ Congresso USP de Controladoria e Contabilidade, 2005, São Paulo. Anais do $5^{\circ}$ Congresso USP de Controladoria $e$ Contabilidade. São Paulo.

SOUTES, D. O.; GUERREIRO, R. Uma Investigação do Uso de Artefatos de Contabilidade Gerencial em Empresas Brasileiras. In: XXXI EnANPAD, 2007, Rio de Janeiro. Anais do XXXI EnANPAD. Rio de Janeiro, EnANPAD, 2007. CD-ROM.

SOUZA, M. A.; LISBOA, L. P.; ROCHA, W. Práticas de Contabilidade Gerencial adotadas por Subsidiárias Brasileiras de Empresas Multinacionais. Revista Contabilidade \& Finanças RCF. São Paulo: n. 32. p. 40-57. Mai. / Ago. 2003.

STONER, J. A. F.; FREEMAN, R. E. Administração. 5 ed. Rio de Janeiro: Prentice-Hall do Brasil, 1985. 
TILLEMA, S. Towards an integrated contingency framework for MAS sophistication - case studies on the scope of accounting instruments in Dutch power and gas companies. Management Accounting Research, volume 16, issue 1, p.101-129, March 2005.

TOLBERT, P. S.; ZUCKER, L. G; A Institucionalização da Teoria Institucional. In: CLEGG, Stewart R.; HARDY, Cynthia; NORD, Walter R. Handbook de Estudos Organizacionais. v. 1. São Paulo: Atlas, 1999. p. 193-217.

VOLLMER, H. Managemente Accounting as Normal Social Science. Accounting, Organizations and Society. v. 34. p. 141-150. 2009.

WALSH, R. N.; VAUGHAN, F. Além do Ego: Dimensões Transpessoais em Psicologia. São Paulo: Cultrix/Pensamento, 1980.

YOUNG-EISENDRATH, P.; DAWSON, T. Manual de Cambridge para Estudos Junguianos. Porto Alegre: Artmed Editora, 2002.

ZAN, A. Mudanças na Contabilidade Gerencial de uma Organização: Estudo de Caso com diagnóstico Institucional. São Paulo, 2006. Dissertação (Mestrado em Contabilidade) Programa de Pós-Graduação em Administração, Faculdade de Economia, Administração e Contabilidade da Universidade de São Paulo, São Paulo.

\section{ENDEREÇO DOS AUTORES}

Universidade Federal do Paraná Setor de Ciências Sociais Aplicadas Av. Prefeito Lothário Meissner, 632 - Jd Botânico Curitiba, PR - Brasil 80210-170 